http://dx.doi.org/10.1590/1678-49442018v24n1p271

CAUSEY, Andrew. 2017. Drawn to See. Drawing as an Ethnographic Method. Toronto: University of Toronto Press. 171 pp. (72 imagens)

\section{Karina Kuschnir}

Departamento de Antropologia Cultural, Instituto de Filosofia e Ciências Sociais, Universidade Federal do Rio de Janeiro/ RJ, Brasil.

Numa época de desconstruções e desalentos, Andrew Causey nos oferece uma dádiva. Drawn to See: Drawing as an Ethnographic Method é precioso para quem quer continuar acreditando que a antropologia é possível sem abdicar de uma postura crítica, reflexiva e renovadora. A obra enfrenta com seriedade os problemas teóricos do projeto etnográfico, e propõe soluções metodológicas amparadas em situações vividas no trabalho de campo do autor ou dos autores citados na excelente bibliografia. Textos e ilustrações formam um conjunto de leitura extremamente agradável. Trata-se de um caso raro de obra que consegue refletir, experimentar, demonstrar, propor sem deixar de apontar lacunas e nos fazer sorrir pelo caminho.

Drawn to See é teóricometodológico, mas também é memorialista e pessoal - um diário escrito e gráfico do autor sobre sua trajetória como etnógrafo. Seu valor está nessas múltiplas camadas narrativas, nas quais vida, pesquisa e obra surgem imbricadas numa saudável antropologia. A etnografia é entendida não apenas como produção de conhecimento, mas de relações, afetos, sensações, visualidades, compartilhamentos, respeito e comunicação. O aprendizado do desenho é central, mas ao mesmo tempo secundário ao objetivo de nos ajudar a ver o mundo (visível e invisível) de modo mais aprofundado, focado e ativo, numa busca por conciliar observação e participação - dois pilares da metodologia antropológica.

O livro divide-se em sete capítulos, pelos quais se espalham 72 ilustrações. Além do debate sobre antropologia, imagem e pesquisa, a obra tem como eixo central ensinar antropólogos a desenhar. Causey inclui 39 exercícios, que chama de "Etudes" (Estudos), palavra que remete às partituras feitas para se aperfeiçoarem as técnicas e as habilidades dos músicos. Seu objetivo não é formar artistas, mas sim estimular o uso do desenho linear como modo de contribuir para a pesquisa de campo. Os materiais sugeridos são simples. Lápis, papel comum, canetinha de ponta porosa e guardanapos são as únicas coisas necessárias para realizar as propostas. Adiantando-se às possíveis resistências de seus leitores acadêmicos, o autor propõe uma lista das predisposições necessárias para começar: relaxar, focar (sentir), 
concentrar, desacelerar, aceitar (sem avaliações, sem notas, sem comparações), se interessar (ter curiosidade), desenhar o que se vê, desprender-se do ego, praticar.

Como se percebe ao longo da leitura, tais conselhos são fruto das experiências do autor ao longo de sua trajetória como artista e antropólogo. Hoje professor de Antropologia Cultural do Columbia College de Chicago, Causey fez mestrado e doutorado na Universidade do Texas, Austin, local cuja tradição ajuda a compreender sua crença no projeto etnográfico, felizmente, sem deixar de enfrentar seus paradoxos e dificuldades. Sua pesquisa de campo se deu entre os Toba Batak, em Samosir, ilha vulcânica localizada no interior do Lago Toba, ao norte de Sumatra, Indonésia. Um lugar incrível (experimentem digitar Samosir Island nas imagens do Google) que atrai turistas do mundo inteiro, situação que acabou sendo o foco da pesquisa de Causey, em 1994-1995, com um retorno em 2012. O etnógrafo tornou-se aprendiz de Partoho, artista local, escultor em madeira, que, junto com sua esposa Ito, foi seu principal interlocutor no campo.

A leitura permite acompanharmos a ressignificação do uso do desenho na antropologia desde os anos 1990, quando a pesquisa inicial foi feita, e os anos 2015-2017, quando o livro é encomendado, escrito e publicado.
$\mathrm{Na}$ época em que terminou o doutorado, Causey chegou a expor no campus da universidade seus desenhos e pinturas feitos durante a etnografia. As imagens que retratavam pessoas, no entanto, tiveram de ser retiradas do local, sob o argumento de que não eram sérias o suficiente e poderiam mostrar-se ofensivas à população estudada. Naquela altura, pouco se discutia a possibilidade de se utilizarem os registros gráficos (croquis, esboços, desenhos, aquarelas, pinturas) como parte do conceito de antropologia visual, então voltada para o uso da fotografia e do filme.

Um dos grandes méritos de Drawn to See é contribuir para a ampliação e a consolidação da ideia, cada vez mais fortalecida na literatura recente, de que a imagem desenhada pode - e deve - voltar a assumir mais protagonismo no empreendimento etnográfico. O livro tem impacto muito maior do que seu objetivo declarado de "ensinar o desenho linear, como uma das opções para coletar, registrar, documentar e apresentar a informação etnográfica" (:3, tradução minha). Tínhamos até o momento bons livros de ensino de desenho, de um lado; e bons livros de antropologia, do outro. Existem bons artigos sendo publicados sobre a relação entre as áreas, sem dúvida. Mas esta é a primeira obra de fôlego a enfrentar de forma densa - tanto teórica quanto empírica - a maneira de unir o melhor dos dois mundos. 
Na esfera do desenho, os 39 Estudos propostos são claros e acessíveis. O objetivo do autor é que sejam experimentados por todos. Nesse sentido, parece-me acertada a escolha do desenho linear como eixo dos exercícios, uma vez que é a linguagem de produção gráfica mais próxima do universo de pessoas alfabetizadas. Uma das propostas inovadoras e interessantes de Causey é a utilização de formas essenciais baseadas em números e letras. Aideia de recorrer a elementos primários (pontos, retas e curvas) para elaborar figuras complexas não é nova, mas o apoio em formas numéricas e alfabéticas é uma bemvinda criação do autor. Junto com as chaves de percepção dos Estudos 1 e 2, as propostas 3 e 4 formam um conjunto simples mas bastante eficaz para se desenvolver a habilidade de enxergar pelo desenho.

Nos 35 Estudos seguintes, Causey alterna sugestões mais relaxadas com outras mais elaboradas, numa coleção estimulante e divertida, mas também reflexiva e cuidadosa. Os exercícios têm um bom destaque gráfico no livro, pois estão impressos em fundo cinza, com ilustrações acompanhando a explicação textual. A série e todas as 72 imagens da obra estão numeradas de forma clara e contêm a duração aproximada de sua realização. O tempo estimado da grande maioria dos Etudes (33 em 39) é inferior a 10 minutos; apenas dois levariam de 10 a 15 minutos; e quatro não têm um intervalo definido. A curta duração é atraente para os novatos e estratégica para provar, mesmo aos mais céticos, que não é preciso 10 mil horas de prática para produzir desenhos etnograficamente relevantes. A ideia é pavimentar um caminho para ver, enxergar, perceber, como enfatiza o título do livro.

Pelo lado da antropologia, Drawn to see aborda questões complexas com a mesma clareza com que apresenta os exercícios visuais. Como destaquei acima, Causey enfrenta a problemática da dupla tarefa de "observar" e "participar", assim como inúmeras questões associadas ao projeto etnográfico. Da necessidade de atenção, registro e memorização, passando pelo diálogo e pelas subjetividades de pesquisadores e interlocutores, o autor aborda problemas na produção de conhecimento antropológico, nas ideias de representação, temporalidade, movimento, memória, corporalidade, entre outras. E tudo isso alinhavado por um profundo comprometimento com a ética na etnografia, como mostram os vários exemplos que nos convidam a aprender com as dúvidas, as falhas e as dificuldades do próprio Causey em campo. Chama a atenção o tom equilibrado e sensato da linguagem do autor, demonstrando respeito, empatia e interesse pelo universo investigado, sem sinal 
da soberba, do paternalismo e da assertividade messiânica que infelizmente tanto frequentam a literatura antropológica.

Figura 1. Desenho de Andrew Causey feito a partir de suas lembranças de campo. Na legenda original se lê: “Ito, debilitada pela artrite, senta em sua mesa de cozinha, de sua casa reconstruída, falando no celular sem parar com um de seus oito filhos. Ela me entrega o telefone sem me dizer com quem estou falando, dizendo: ‘Omong! Omonglah sama dia!'”

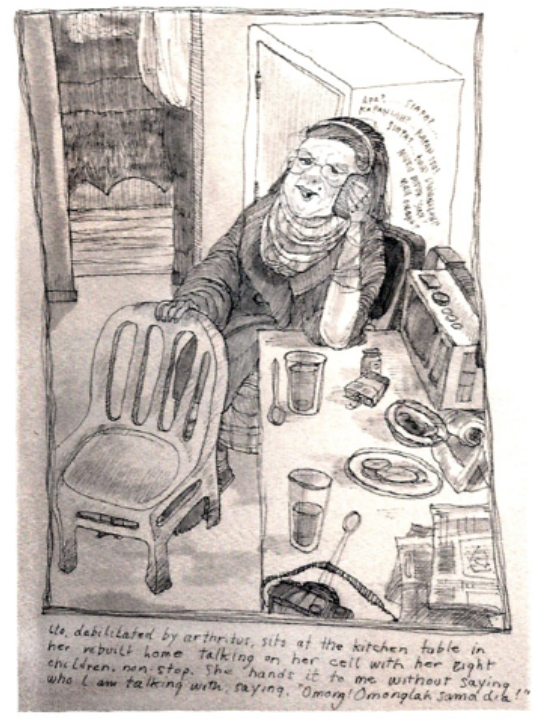

Esse mesmo senso ético pode ser observado na forma como o autor lida com sua rede de apoio intelectual e com a bibliografia consultada. Cada imagem, quando não de sua autoria, é publicada com aviso de permissão e referência ao/à autor/a ou fonte. As citações aos autores, aos artigos e às obras consultadas são claras e precisas, sempre com indicação das páginas correspondentes. O destaque de cada uma, no texto ou em notas, é compatível com sua relevância para o argumento em pauta. Muitos Estudos indicam as fontes que os inspiraram, sejam obras ou comunicações orais. A pesquisa bibliográfica é em si mesma um empreendimento notável do livro, pois traz um levantamento exaustivo, especialmente em língua inglesa. É consulta indispensável para todos os que se interessam pelo tema.

Entre as muitas qualidades de Drawn to See estão as histórias do trabalho de campo do autor. Atuando como aprendiz de Partoho, Causey percebe o quanto seus olhos não veem da mesma maneira. Ao copiar um desenho do mestre, é corrigido por registrar "errado", num senso estético alheio aos Toba Batak. Divertimo-nos em vários momentos do livro com as críticas dos interlocutores às imagens do etnógrafo, ora por não perceber detalhes culturalmente relevantes, ora por representar de forma irônica, errada, distorcida ou fragmentada aquilo que lhes parecia correto, decente ou óbvio. Numa das ocasiões, algumas mulheres tomam o caderno do pesquisador e exigem que o retrato de uma delas seja refeito até ficar satisfatório. 
A reação de Causey é animadora: desenhar é aceitar riscos; é gerar experiências memoráveis e revolucionárias; é pressupor que o pesquisador "não sabe o que não sabe". As imagens são notas, documentos de campo que se dão a ver. Não é preciso se desculpar, mas sim aprender com os diálogos, as reações e as interpretações. Todo desenho etnográfico vale a pena, desde que seja uma criação ética, moral e intelectualmente responsável. Sob este aspecto, é tocante o caso de uma entrevista feita pelo etnógrafo com um veterano de guerra, viúvo, cuja fama social era a de arrogante e orgulhoso. Desse encontro, que reverte suas expectativas, o autor não faz registros gráficos ou textuais. Olha nos olhos, exercita sua visão periférica na penumbra, aceita a memorização e o silêncio como parte da experiência. Nem tudo, afinal, pode (ou deve) ser registrado.

Nos capítulos finais, Causey se pergunta como ultrapassar as superfícies, como trazer à tona as estruturas e as motivações que animam pessoas, coisas e animais. Suas respostas em textos e imagens são de uma rara beleza: revelam-se mais como perguntas do que soluções; são imperfeitas e tentativas; são portas que se abrem para dar sentido ao mundo possibilidades dentro do impossível projeto etnográfico. http://dx.doi.org/10.1590/1678-49442018v24n1p275

DAS, Veena. 2015. Affliction: health, disease, poverty. New York: Fordham University Press. 256 pp.

\section{Raphael Bispo}

Mestre e Doutor em Antropologia Social pelo Museu Nacional/ Universidade Federal do Rio de Janeiro (UFRJ), Professor Adjunto do Programa de Pós-Graduação em Ciências Sociais (PPGCSO)/ Universidade Federal de Juiz de Fora/MG, Brasil.

"Eu mencionei a você minhas notas altas, não é mesmo? Mas eu não pude mostrar como eu fui bem na escola para a mamãe" (:78). A declaração em tom de lamento é de Mukesh, 8 anos de idade, dita à antropóloga Veena Das quando retornava à casa da criança na periferia de Nova Delhi e recebe a notícia da morte por tuberculose da mãe dele, Meena. Esta e outras tocantes falas compõem a narrativa de Affliction - a mais recente etnografia dessa influente pesquisadora indiana cujos desconcertantes sentimentos que provoca nos leitores são aqui impossíveis de serem reavivados em toda a sua intensidade. Isto porque Das aprofunda neste trabalho a proposta que tem marcado sua trajetória intelectual ao dedicar-se mais uma vez ao estudo das formas com que as pessoas resistem e recuperam suas vidas que, por alguma razão, são devastadas pela 